\title{
Tuberculosis, HIV/AIDS and Diabetes - Is it Time to Think Together?
}

\author{
Ramalingam Sekar and Manoharan Mythreyee* \\ Department of Microbiology, Faculty of Medicine, Government Theni Medical College, The Tamilnadu Dr. MGR Medical University, Theni, India
}

\begin{abstract}
Human Immunodeficiency Virus (HIV)/Acquired Immunodeficiency Syndrome (AIDS), Tuberculosis (TB) and Diabetes mellitus (DM) were individually one of the top ten causes of mortality all over the world. Dreadfully, all together these three killers claim 4.38 million lives in each year, which correspond to $7.7 \%$ of total deaths/annum. The association between HIV and TB were well recognized, and the control measures were already constructed, implemented and working well. Whereas, the evidences were growing for the association between TB and DM as well as HIV and DM. Hence, we are in the need to construct an interlinked screening, diagnosis, treatment, prevention and counseling strategy for all TB, Diabetic and HIV patients to control the morbidity and mortality associated with these deadly diseases. At least, as a cost effective measure, all the diabetic patients should be screened for TB and vice versa, similar to the lesson learned from HIV-TB association and, HIV patients on anti-retroviral therapy should be monitored for hyperglycemia and the development of DM. Such a strategy would lead to earlier case detection, improve the management of all the three deadly diseases, and reduce the mortality significantly.
\end{abstract}

Keywords: HIV; Tuberculosis; Diabetes; Incidence; Risk; Control

\section{Background}

Human Immunodeficiency Virus (HIV)/Acquired Immunodeficiency Syndrome (AIDS), Tuberculosis (TB) and Diabetes mellitus (DM) were individually one of the top ten causes of mortality all over the world [1]. Annual deaths caused by these diseases were 1.78 million, 1.34 million and 1.26 million respectively. Dreadfully, all together these three killers claim 4.38 million lives, which correspond to $7.7 \%$ of total deaths/annum. Among the three killers two are chronic communicable disease i.e., HIV and TB; and the other is chronic noncommunicable disease i.e., DM. The association between communicable and noncommunicable diseases were known for centuries but are neglected until recently [2]. Intriguingly, in the recent past evidences were accumulating on the association between TB and DM, as well as HIV/ AIDS and DM, which gained importance to the communicable - noncommunicable disease association [3]. Nevertheless, the HIV-TB link was well recognized since the beginning of HIV epidemic. Hence, this editorial is attempted to review the evidence and counter-evidence stating the association between these three deadly diseases in relation to aetiopathogenesis, diagnosis and management.

\section{Tuberculosis and Diabetes}

Tuberculosis holding a persistent top position among the fatal infections of bacterial diseases all over the world [1,4]. According to the World Health Organization (WHO) report, there are about 8.8 million new TB cases and 1.45 million deaths owing to TB in the year of 2010 [5]. However, in recent past, TB incidence has declined in developed countries, but the incidence remains high in developing and underdeveloped countries. Awfully, it is estimated that $1 / 3$ of the world population i.e., $\sim 2$ billion were latently infected with Mycobacterium tuberculosis and may get progressed to active TB at any time of life, especially during the immunosuppression. At the same time, the prevalence of diabetes mellitus is increasing globally in an alarming manner. As estimated by Wild et al. [6] the prevalence of DM was 171 million or $2.8 \%$ in the year of 2000 . Shockingly, the estimated prevalence was more than doubled within the short period of 10 years. According to International Diabetes Federation report, the global prevalence of DM was estimated to be 366 million or $8.3 \%$ in the year of 2011 and is expected to surge to 552 million or $9.9 \%$ people, by 2030 [6,7].

The relationship between $\mathrm{TB}$ and $\mathrm{DM}$ has been recognized for centuries [8]. In the middle of twentieth century, there were reports on the association between TB and DM, stating that, merging the management of these diseases could improve the patient outcome [911]. However, until recent years [12], there was a lack of strong evidence on the strength of the association between TB and DM. Presently the association between the TB and DM are poorly acknowledged. The link was not even mentioned in many global and national TB control strategies yet it is plausible that diabetes is a major threat to effective TB control [3,5].

According to a recent meta-analysis, diabetes patients have three times the risk of contracting TB as non-diabetics [2] and studies report the portion of TB cases ascribable to diabetes to be between $15 \%$ and $25 \%[13,14]$. The WHO suspects that the TB control could become difficult, as there is alarming rise in the prevalence of DM patients across the globe [15]. The biological mechanism for the association between TB and DM is not fully understood but studies suggest that diabetes depresses the immune response [16], which in turn facilitates the progression of latently infected Mycobacterium tuberculosis to active TB disease.

Furthermore, the incidence of multi-drug resistant TB (MDR-TB) was also reported to be high among DM patients owing to the impaired absorption of anti-TB drugs in the gastrointestinal mucosa, which

${ }^{*}$ Corresponding author: Dr. K. M. Mythreyee., M.D., Professor \& Head, Department of Microbiology, Government Theni Medical College, The Tamilnadu Dr. MGR Medical University, Theni, India, Tel: +91-4546-244602; Fax: +91 4546-243502; E-mail: drmythreyee@gmail.com

Received December 08, 2011; Accepted January 01, 2012; Published January 07, 2012

Citation: Sekar R, Mythreyee M (2012) Tuberculosis, HIVIAIDS and Diabetes - Is it Time to Think Together? J Medical Microbiol Diagnosis 1:e103. doi:10.4172/21610703.1000e103

Copyright: @ 2012 Sekar R, et al. This is an open-access article distributed under the terms of the Creative Commons Attribution License, which permits unrestricted use, distribution, and reproduction in any medium, provided the original author and source are credited. 
Citation: Sekar R, Mythreyee M (2012) Tuberculosis, HIVIAIDS and Diabetes - Is it Time to Think Together? J Medical Microbiol Diagnosis 1:e103. doi:10.4172/2161-0703.1000e103

resulted in the sub-lethal dose achievement at the tissue level where the bacteria exist, and facilitate the development of drug resistance [17-19]. However, it was not supported by other studies $[20,21]$ and uncertainty remains.

Although the many number of studies evaluated the presence of diabetes as a risk factor for TB [12,22], the connection between DM and TB is suggested to be bidirectional. According to the reports by Nichols et al. [23] and Karachunskii et al. [24], TB could increase the risk of developing diabetes. However, ambiguity remains around whether TB is a risk factor for DM.

Therefore, it is obvious that patients with diabetes are at higher risk of developing active TB than non-diabetic patients [2,12]. Integrating $\mathrm{TB}$ and diabetes control programs worldwide would facilitate TB prevention among diabetes patients. Such a strategy would provide a way to earlier case detection and improve the management of both TB and diabetes.

\section{Diabetes and HIV/AIDS}

According to the recent UNAIDS report, 33.3 million people were estimated to be living with HIV/AIDS [25]. Sub-Saharan Africa sustained to hold a maximum share of the global burden of HIV patients and AIDS related deaths.

The association between HIV infection and DM is poorly understood. According to Butt et al. [26] HIV infection is not having direct association with DM; however, the intake of anti-retroviral therapy (ART) increases the risk of developing DM. According to Brown et al. $[27,28]$ the incidence of DM was 4 times higher among the persons taking highly active ART (HAART), than that of HIV uninfected persons.

ART is the only approved tool for the management and control of HIV/AIDS disease progression. It consists of a number of drugs that suppresses viral multiplication and decreases the viral load. HAART is the gold standard for the management of AIDS, where three or more drugs are combined together in order to prevent the development of drug resistance in HIV. According to recent report of UNAIDS, ART was currently put on more than 5 million HIV infected persons [25].

Patients living with HIV/AIDS (PLHA) are increasing in number, partly owing to improved screening strategy (earlier diagnosis of HIV), better treatment and monitoring options (management of opportunistic infections and monitoring of CD4 cell count at regular intervals), and greater accessibility to ART at government centers with free of cost - altogether help improve the survival of these patients. Consequently, HIV/AIDS associated mortality was reported to be significantly declining in the recent past. Addition of newer cases and the endurance of previously diagnosed cases, results in the increasing number of PLHA [25].

However, the major problem with ART is, once started it should be continued for entire life. This resulted in an augmented exposure to ART and caused chronic complications due to drug toxicity among them. Hence, PLHA taking ART frequently presents with diabetes and other metabolic complaints [29]. The prevalence of hyperglycemia and diabetes mellitus is significantly higher in PLHA being treated with ART, as compared with the general population [29-32]. Therefore, as number of PLHA increases, the incidence of HIV-associated diabetes is also bound to grow. There are three subgroups of diabetes among
PLHA: the most important subgroup in relation to HIV associated diabetes is developing hyperglycemia after the initiation of ART, other two subgroups were, patients with preexisting diabetes, and those who are diagnosed to have diabetes at the time of HIV diagnosis. The management of diabetes in these three PLHA subgroups were different, since the mechanisms of metabolic dysregulation vary in them [29].

The aetiopathogenesis of DM in PLHA were mainly insulin resistance, rather than insulin deficiency. Reportedly, insulin resistance is common in HIV-infected people, particularly among those being treated with protease inhibitor. It is hypothesized that, protease inhibitor (PI) confer acute metabolic risks, while nucleoside reverse transcriptase inhibitor (NRTI) confers cumulative risks of diabetes in exposed, predisposed persons. Exposure to a combination of NRTI and PI has synergistic effect on the onset of diabetes [33]. Takarabe and Rokukawa [34] recently reported the autoimmune mechanism of DM among the HIV infected persons during the restoration of immunity after the initiation of HAART.

Therefore, it is strongly recommended that, the patients with HIV should be screened for diabetes at the time of HIV diagnosis, at the initiation of HAART, and three to six months after HAART.

\section{HIV/AIDS and Tuberculosis}

The association between TB and HIV was well recognized, since the early years of HIV epidemic. Their dangerous synergy affects all aspects of both the diseases, from pathogenesis and epidemiology; to clinical manifestation, treatment, and prevention. The greatest burden of the TB-HIV co-infection was observed in sub-Saharan Africa.

Individually, both HIV and TB were the two leading causes of infectious disease associated mortality worldwide [1]. Additionally, TB is the leading cause of death among PLHA. Nearly one in four deaths among people with HIV is owing to TB. According to the recent WHO report [5,35], 1.1 million new TB cases were estimated among the HIV patients in 2010. Among them around $82 \%$ of patients was living in sub-Saharan Africa.

At least one-third of the 33.3 million people living with HIV worldwide are latently infected with TB. The HIV-TB co-infected persons are 21-34 times more likely to develop active TB disease, than the persons without HIV [35]. The HIV-TB co-infection can occur in two forms: person with latent TB acquire HIV infection or HIV infected person acquire new TB infection. In both the cases, the risk of developing active TB increases several fold. According to Chaisson et al. [36] the risk of reactivation of latent TB infection, increases to 100fold, when a person acquires HIV infection. More importantly, PLHA need early diagnosis and treatment of active TB disease; and if TB was not present, they should receive Isoniazid preventive therapy $[5,35]$.

The increasing incidence of MDR-TB and the emerging problem of extensively drug-resistant TB (XDR-TB), were reported to be more common in HIV infected and are most problematic for the management (Table 1). The drug resistant forms worsen the management of active TB cases, and are responsible for very high mortality rate among PLHA and may undermine the current TB control strategies especially in low and middle-income countries $[37,38]$.

HIV-TB co-infection complicates both the diagnosis and treatment of tuberculosis. Because the sputum smear microscopy in HIV infected persons were, reportedly having reduced sensitivity than that of HIV uninfected persons. The treatment of HIV-TB co-infection includes the 
Citation: Sekar R, Mythreyee M (2012) Tuberculosis, HIVIAIDS and Diabetes - Is it Time to Think Together? J Medical Microbiol Diagnosis 1:e103. doi:10.4172/2161-0703.1000e103

concomitant administration of both anti-tuberculosis therapy (ATT) and ART. The most common treatment challenges include, pill burden and overlapping toxic effects of ATT and ART, drug interactions, patient compliance and immune reconstitution inflammatory syndrome. Current treatment guideline for the HIV-TB co-infection is starting ART within a few weeks of ATT for patients with CD4 cell count $<350$ cells $/ \mu \mathrm{L}$; however, when to start $\mathrm{ART}$ and what to start remain ambiguous in HIV-TB management [39].

\section{Tuberculosis, HIV/AIDS and Diabetes}

It has long been recognized that infective agents may predispose to, or trigger, some chronic noncommunicable diseases [11]. Now, it has become evident that two of the most common infectious diseases, TB and HIV, may also be closely related to chronic noncommunicable disease [3]. Based on the available evidence, it is clearly understood that, diabetes predisposes to TB [2,13], whereas with limited evidence TB may also predispose to diabetes [40]. ART for HIV/AIDS may increase the risk of metabolic syndrome and thus predispose to DM (Figure 1) [27,30]. Hence, we call for the action of considering all the three diseases together for diagnosis and management to improve the case detection, early treatment and possible prevention.

Although, the current evidences suggest the strong association between HIV, TB and DM much research is needed to arrive conclusion, especially the combined effect of HIV and DM on TB is yet to be unveiled (Table 1). Nevertheless, integrating HIV/AIDS, TB and diabetes control programs in low and middle-income countries would have a great public health impact in preventing TB among HIV and/ or DM patients; and DM among HIV patients. Such a strategy would lead to earlier case detection, improve the management of all the three

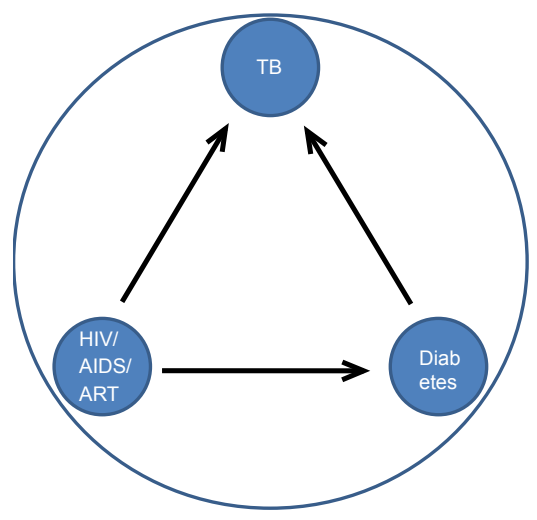

Figure 1: Association between HIVIAIDS, Tuberculosis and Diabetes mellitus.

\begin{tabular}{|l|l|l|l|}
\hline Adverse Outcomes & HIV - TB & DM - TB & (HIV \& DM) - TB \\
\hline Increased TB cases & ++ & + & $?(+++)$ \\
\hline More difficult to diagnose TB cases & Yes & Yes & $?$ (Yes) \\
\hline Increased Death & Yes & Yes & $?$ (Yes) \\
\hline Increased Recurrent TB & Yes & Yes & $?($ Yes) \\
\hline Increased incidence of MDR - TB & Yes & Yes & $?($ Yes) \\
\hline
\end{tabular}

HIV - Human Immunodeficiency Virus Infection

TB - Tuberculosis

DM - Diabetes mellitus

MDR-TB - Multi-Drug resistant TB

Results inside the parenthesis were hypothesized.

Table 1: Assessment of each condition in association with Tuberculosis. deadly diseases, and reduce the mortality significantly

The "Journal of Medical Microbiology \& Diagnosis" (JMMD) is an open access journal, aims to advance our understanding on the medical importance of microorganisms and their capability of causing diseases in human beings. It is an international, peer-reviewed journal, publishing an overview of current research on many aspects of all medically important microorganisms. The journal belongs to OMICS Publishing group, a well-established open access publisher, start gaining reputation by its several unique features, including digital archiving, audio version of the publication, language translation and social networking.

Open access provide, immediate dissemination of knowledge to all readers across the globe at free of cost. Therefore, articles published in open access will have more impact and consequently, more citations than that of any subscription-based journals. Hence, readers and researchers are strongly recommended to submit their research paper to JMMD for the rapid peer-review and immediate publication.

\section{References}

1. WHO (2011) The top 10 causes of death. World Health Organisation.

2. Jeon CY, Murray MB (2008) Diabetes mellitus increases the risk of active tuberculosis: a systematic review of 13 observational studies. PLoS Med 5 : e152.

3. Young F, Critchley JA, Johnstone LK, Unwin NC (2009) A review of comorbidity between infectious and chronic disease in Sub Saharan Africa: TB and diabetes mellitus, HIV and metabolic syndrome, and the impact of globalization. Global Health 5: 9.

4. WHO (2008) The global burden of disease: 2004 update World Health Organisation.

5. WHO (2011) Global Tuberculosis Control World Health Organisation.

6. Wild S, Roglic G, Green A, Sicree R, King H (2004) Global prevalence of diabetes: estimates for the year 2000 and projections for 2030. Diabetes Care 27: 1047-1053.

7. IDF (2011) Diabetes Atlas. International Diabetes Federation.

8. Rajalakshmi S, Veluchamy G (1999) Yugi's pramegam and diebetes mellitus: an analogue. Bull Indian Inst Hist Med Hyderabad 29: 83-87.

9. Brock BL (1957) The diabetic patient with tuberculosis. J Lancet 77: 238-242.

10. Ferrara MA (1952) The tuberculous diabetic patient. N Engl J Med 246: 55-56

11. Root HF (1934) The Association of Diabetes and Tuberculosis. N Engl J Med 210: 78-92.

12. Stevenson CR, Critchley JA, Forouhi NG, Roglic G, Williams BG, et al. (2007) Diabetes and the risk of tuberculosis: a neglected threat to public health? Chronic IIIn 3: 228-245.

13. Stevenson CR, Forouhi NG, Roglic G, Williams BG, Lauer JA, et al. (2007) Diabetes and tuberculosis: the impact of the diabetes epidemic on tuberculosis incidence. BMC Public Health 7: 234.

14. Ponce-De-Leon A, Garcia-Garcia Md Mde L, Garcia-Sancho MC, GomezPerez FJ, Valdespino-Gomez JL, et al. (2004) Tuberculosis and diabetes in southern Mexico. Diabetes Care 27: 1584-1590.

15. Restrepo BI, Camerlin AJ, Rahbar MH, Wang W, Restrepo MA, et al. (2011) Cross-sectional assessment reveals high diabetes prevalence among newlydiagnosed tuberculosis cases. Bull World Health Organ 89: 352-359.

16. Geerlings SE, Hoepelman Al (1999) Immune dysfunction in patients with diabetes mellitus (DM). FEMS Immunol Med Microbiol 26: 259-265.

17. Fisher-Hoch SP, Whitney E, McCormick JB, Crespo G, Smith B, et al. (2008) Type 2 diabetes and multidrug-resistant tuberculosis. Scand J Infect Dis 40: 
Citation: Sekar R, Mythreyee M (2012) Tuberculosis, HIVIAIDS and Diabetes - Is it Time to Think Together? J Medical Microbiol Diagnosis 1:e103. doi:10.4172/2161-0703.1000e103

888-893

18. Nijland HM, Ruslami R, Stalenhoef JE, Nelwan EJ, Alisjahbana B, et al. (2006) Exposure to rifampicin is strongly reduced in patients with tuberculosis and type 2 diabetes. Clin Infect Dis 43: 848-854.

19. Subhash HS, Ashwin I, Jesudason MV, Abharam OC, John G, et al. (2003) Clinical characteristics and treatment response among patients with multidrugresistant tuberculosis: a retrospective study. Indian J Chest Dis Allied Sci 45: 97-103.

20. Suarez-Garcia I, Rodriguez-Blanco A, Vidal-Perez JL, Garcia-Viejo MA, JarasHernandez MJ, et al. (2009) Risk factors for multidrug-resistant tuberculosis in a tuberculosis unit in Madrid, Spain. Eur J Clin Microbiol Infect Dis 28: 325-330.

21. Tanrikulu AC, Hosoglu S, Ozekinci T, Abakay A, Gurkan F (2008) Risk factors for drug resistant tuberculosis in southeast Turkey. Trop Doct 38: 91-93.

22. Baker MA, Harries AD, Jeon CY, Hart JE, Kapur A, et al. (2011) The impact of diabetes on tuberculosis treatment outcomes: a systematic review. BMC Med 9: 81 .

23. Nichols GP (1957) Diabetes among young tuberculous patients; a review of the association of the two diseases. Am Rev Tuberc 76: 1016-1030

24. Karachunskii MA, Beglarian NR, lakovleva OB (1993) Clinical aspects of pulmonary tuberculosis in patients with borderline disorders of carbohydrate metabolism. Probl Tuberk: 16-17.

25. UNAIDS (2010) Report on the Global AIDS Epidemic.

26. Butt AA, McGinnis K, Rodriguez-Barradas MC, Crystal S, Simberkoff M, et al. (2009) HIV infection and the risk of diabetes mellitus. AIDS 23: 1227-1234.

27. Brown TT, Cole SR, Li X, Kingsley LA, Palella FJ, et al. (2005) Antiretroviral therapy and the prevalence and incidence of diabetes mellitus in the multicenter AIDS cohort study. Arch Intern Med 165: 1179-1184.

28. Brown TT, Tassiopoulos K, Bosch RJ, Shikuma C, McComsey GA (2010) Association between systemic inflammation and incident diabetes in HIVinfected patients after initiation of antiretroviral therapy. Diabetes Care 33: 2244-2249.
29. Kalra S, Kalra B, Agrawal N, Unnikrishnan A (2011) Understanding diabetes in patients with HIVIAIDS. Diabetol Metab Syndr 3: 2 .

30. Aboud M, Elgalib A, Kulasegaram R, Peters B (2007) Insulin resistance and HIV infection: a review. Int J Clin Pract 61: 463-472.

31. Paik IJ, Kotler DP (2011) The prevalence and pathogenesis of diabetes mellitus in treated HIV-infection. Best Pract Res Clin Endocrinol Metab 25: 469-478.

32. Gupta S, Shenoy VP, Bairy I, Srinivasa H, Mukhopadhyay C (2011) Diabetes mellitus and HIV as co-morbidities in tuberculosis patients of rural south India J Infect Public Health 4: 140-144.

33. De Wit S, Sabin CA, Weber R, Worm SW, Reiss P, et al. (2008) Incidence and risk factors for new-onset diabetes in HIV-infected patients: the Data Collection on Adverse Events of Anti-HIV Drugs (D:A:D) study. Diabetes Care 31: 12241229.

34. Takarabe D, Rokukawa Y, Takahashi Y, Goto A, Takaichi M, et al. (2010) Autoimmune diabetes in HIV-infected patients on highly active antiretroviral therapy. J Clin Endocrinol Metab 95: 4056-4060.

35. WHO (2011) TB/HIV Facts. World Health Organisation.

36. Chaisson RE, Martinson NA (2008) Tuberculosis in Africa--combating an HIVdriven crisis. N Engl J Med 358: 1089-1092.

37. Gandhi NR, Moll A, Sturm AW, Pawinski R, Govender T, et al. (2006) Extensively drug-resistant tuberculosis as a cause of death in patients coinfected with tuberculosis and HIV in a rural area of South Africa. Lancet 368 1575-1580.

38. Gandhi NR, Nunn P, Dheda K, Schaaf HS, Zignol M, et al. (2010) Multidrug resistant and extensively drug-resistant tuberculosis: a threat to global control of tuberculosis. Lancet 375: 1830-1843.

39. Swaminathan S, Padmapriyadarsini C, Narendran G (2010) HIV-associated tuberculosis: clinical update. Clin Infect Dis 50: 1377-1386.

40. Mugusi F, Swai AB, Alberti KG, McLarty DG (1990) Increased prevalence of diabetes mellitus in patients with pulmonary tuberculosis in Tanzania. Tubercle 71: 271-276. 